\title{
Efeitos da lixiviação e salinidade da água sobre um solo salinizado cultivado com beterraba
}

\author{
Paulo A. Ferreira ${ }^{1}$, Ronaldo F. de Moura ${ }^{2}$, Delfran B. dos Santos ${ }^{1}$, Paulo C. R. Fontes ${ }^{1} \&$ Ralini F. de Melo
}

\begin{abstract}
RESUMO
Os efeitos de cinco lâminas de lixiviação e quatro níveis de salinidade da água de irrigação sobre a salinidade de um Neossolo Flúvico e a produtividade da cultura da beterraba (Beta vulgaris L.) foram estudados em lisímetros de drenagem. Os tratamentos foram dispostos em arranjo fatorial com quatro níveis de condutividade elétrica da água de irrigação $\left(1,0,2,0,3,0\right.$ e 4,0 dS m-1, a $\left.25^{\circ} \mathrm{C}\right)$ e cinco lâminas de lixiviação equivalente a 0,25, 0,50, 0,75, 1,00 e 1,25 do volume de poros do solo ou 53, 106, 159, 206 e $248 \mathrm{~mm}$, respectivamente, no delineamento inteiramente casualizado, com quatro repetições. Os componentes avaliados foram a produtividade da cultura e as salinidades no solo e no lixiviado. Os resultados obtidos mostraram incrementos da salinidade no lixiviado com o decréscimo das lâminas de lixiviação. Os maiores índices de salinidade no perfil do solo, ao final do ciclo da cultura, corresponderam aos tratamentos que receberam as menores lâminas de lixiviação e condutividade elétrica da água de irrigação. A produtividade total da beterraba e a produção das raízes com diâmetros maiores que 3, 4, 5, 6 e 7 cm, não foram influenciadas pelos níveis de salinidade da água de irrigação e lâminas de lixiviação.
\end{abstract}

Palavras-chave: lisímetros de drenagem, lixiviação de sais, condutividade elétrica

\section{Effects of leaching and water salinity on a saline soil cultivated with sugar beet}

\begin{abstract}
The effects of five leaching depths and four salinity levels of the irrigation water on the salinity of a Neossol Fluvent and the productivity of sugar beet crop were studied using drainage lysimeters. A completely randomized experimental design was used with four replications, the treatments being displayed in a factorial scheme with four electrical conductivity levels of the irrigation water $\left(1.0,2.0,3.0\right.$ and $4.0 \mathrm{dS} \mathrm{m}^{-1}$ at $\left.25^{\circ} \mathrm{C}\right)$ and five leaching depths equivalent to $0.25,0.50$, $0.75,1.00$ and 1.25 of the soil pores volume or 53, 106, 159, 206 e $248 \mathrm{~mm}$, respectively. The crop productivity and the salinity of soil and leachate were evaluated. The results showed increased salinity in the leachate with the decrease in the leaching depth. At the end of the crop cycle, the highest salinity in the soil profile corresponded to treatments receiving both the lowest leaching depths and water salinities. The total sugar beet productivity and the yield of the roots with diameters larger than 3, 4, 5, 6 and $7 \mathrm{~cm}$ were not affected by the salinity levels of the irrigation water nor the leaching depths.
\end{abstract}

Key words: drainage lysimeter, salt leaching, electrical conductivity 


\section{INTRODUÇÃO}

Solos e águas afetados por sais são encontrados extensivamente nas regiões de clima árido e semi-árido, sob condições naturais; entretanto, os maiores problemas de salinidade na agricultura se devem ao resultado das atividades agrícolas que tornam salinizados água e solos, anteriormente produtivos (Richards, 1954; Daker, 1984; Rhoades et al., 1999).

Apesar dos avanços tecnológicos, milhões de hectares continuam sendo salinizados contribuindo severamente para a redução da produção agrícola mundial (Khan \& Abdullah, 2003). Estima-se que aproximadamente um terço da área irrigada mundial se apresenta degradada em virtude do processo de afetação por sais (Ghassemi et al., 1995).

A irrigação é um instrumento efetivo no aumento da produtividade e na expansão de fronteiras agrícolas, porém sua utilização inadequada pode causar problemas de salinização nos solos, principalmente em regiões áridas e semi-áridas, diminuindo os rendimentos das culturas, ou até mesmo resultando no abandono das terras. A salinização e/ou sodificação é um problema com reflexos econômicos, sociais e ecológicos.

O uso de água de irrigação de má qualidade, associado ao manejo inadequado, além de contribuir diretamente para o acréscimo da concentração salina no solo, pode provocar a elevação do nível do lençol freático e, em conseqüência a ascensão capilar, culminando com o excesso de água e sais na zona radicular (Pizarro, 1985; Ayers \& Westcot, 1991; Bernardo, 1995; Ferreira, 2002; Cordeiro, 2001).

No Nordeste do Brasil, são mais de nove milhões de hectares com problemas de salinidade e/ou alcalinidade. Na Bahia, encontra-se a maior área de solos afetados por sais, cerca de 44\% de áreas salinizadas, seguida pelo Ceará, com aproximadamente 25,5\% (Fageria \& Gheyi, 1997). Destaca-se o Perímetro Irrigado de São Gonçalo, PB, que no final da década de 80 possuía cerca de $40 \%$ da área irrigada afetada por sais e, deste total, aproximadamente $80 \%$ apresentam problema de caráter sódico ou salino-sódico (Cordeiro et al., 1988).

Sem a adoção de tecnologia adequada nessas áreas, a tendência do problema é agravar-se ainda mais, tendo em vista a baixa eficiência no uso da água, simultaneamente com um consumo crescente pressionado pelo aumento da demanda de alimentos, tanto para o consumo interno quanto para exportação.

Quanto à tolerância à salinidade, a beterraba-vermelha (hortícola) é classificada como moderadamente tolerante e a beterraba-açucareira, como tolerante (Ayers \& Westcot, 1991; Ricci et al., 2000).

Objetivou-se, através deste estudo, determinar os efeitos de cinco lâminas de lixiviação e quatro níveis de salinidade da água de irrigação sobre a produtividade da cultura da beterraba e a salinidade de um solo aluvial de uma área abandonada por problemas de salinidade, no perímetro de irrigação de Gorutuba, Minas Gerais.

\section{MATERIAL E MÉTODOS}

\section{Localização e construção dos lisímetros}

O trabalho foi conduzido na área experimental do Depar- tamento de Engenharia Agrícola, localizada no Campus da Universidade Federal de Viçosa (UFV) Viçosa, MG, cujas coordenadas geográficas são $20^{\circ} 45^{\prime}$ de latitude sul e $42^{\circ} 45^{\prime}$ de longitude oeste e altitude de $651 \mathrm{~m}$.

Construiu-se, na área experimental, uma bateria de 20 lisímetros de drenagem, usando-se caixas de cimento-amianto com capacidade de $1,00 \mathrm{~m}^{3}$, medindo $1,08 \mathrm{~m}$ de largura, $1,57 \mathrm{~m}$ de comprimento e $0,70 \mathrm{~m}$ de profundidade, com área útil de 1,70 $\mathrm{m}^{2}$. Para cada lisímetro foi construída uma cobertura removível, com propósito de proteger o experimento da interferência de chuvas.

O solo utilizado foi coletado no perímetro de irrigação Gorutuba, MG, e classificado como Neossolo Flúvico (solo Aluvial Eutrófico) no levantamento efetuado pela UFV (1969). A amostra de solo foi retirada até a profundidade de $50 \mathrm{~cm}$, de uma área abandonada desde 1986, devido a problemas de salinidade.

Foram colocados, em cada lisímetro, 940 kg de solo, passado em peneira de $4 \mathrm{~mm}$, homogeneizado em camadas de aproximadamente $5 \mathrm{~cm}$, objetivando-se formar um perfil com densidade semelhante, até a altura de $50 \mathrm{~cm}$. A densidade do solo resultante desse procedimento foi de $1,27 \mathrm{t} \mathrm{m}^{-3}$.

O solo foi caracterizado físico-hídrico e quimicamente (Tabela 1) de acordo com o manual de métodos e análises de solos, EMBRAPA (1997). As características físico-hídricas incluíram: determinação de granulometria (método da pipeta), argila dispersa em água, grau de floculação, densidade de

Tabela 1. Caracterização físico-hídrica e química do solo usado no experimento

\begin{tabular}{|c|c|}
\hline Característica & Resultados \\
\hline \multicolumn{2}{|l|}{ Retenção de água $\left(\mathrm{kg} \mathrm{kg}^{-1}\right)$} \\
\hline$-10 \mathrm{kPa}$ & 0,30 \\
\hline$-33 \mathrm{kPa}$ & 0,23 \\
\hline$-100 \mathrm{kPa}$ & 0,16 \\
\hline$-300 \mathrm{kPa}$ & 0,11 \\
\hline$-1000 \mathrm{kPa}$ & 0,08 \\
\hline$-1500 \mathrm{kPa}$ & 0,07 \\
\hline Classe textural & Franco \\
\hline Areia grossa $\left(\right.$ dag $\left.\mathrm{kg}^{-1}\right)$ & 6,00 \\
\hline Areia fina (dag kg-1) & 45,2 \\
\hline Silte $\left(\mathrm{dag} \mathrm{kg}^{-1}\right)$ & 35,5 \\
\hline Argila $\left(\right.$ dag $\left.\mathrm{kg}^{-1}\right)$ & 13,7 \\
\hline Densidade de partículas $\left(\mathrm{kg} \mathrm{dm}^{-3}\right)$ & 2,47 \\
\hline Porosidade total $\left(\mathrm{dm}^{3} \mathrm{dm}^{-3}\right)$ & 51,3 \\
\hline Macroporosidade $\left(\mathrm{dm}^{3} \mathrm{dm}^{-3}\right)$ & 10,27 \\
\hline Microporosidade $\left(\mathrm{dm}^{3} \mathrm{dm}^{-3}\right)$ & 41,02 \\
\hline pH em água $(1: 2,5)$ & 5,4 \\
\hline $\mathrm{P}\left(\mathrm{mg} \mathrm{kg}^{-1}\right)$ & 27,2 \\
\hline $\mathrm{Na}^{+}\left(\mathrm{cmol}_{\mathrm{c}} \mathrm{kg}^{-1}\right)$ & 2,86 \\
\hline $\mathrm{K}^{+}\left(\mathrm{cmol}_{\mathrm{c}} \mathrm{kg}^{-1}\right)$ & 0,32 \\
\hline $\mathrm{Ca}^{2+}\left(\mathrm{cmol}_{\mathrm{c}} \mathrm{kg}^{-1}\right)$ & 7,4 \\
\hline $\mathrm{Mg}^{2+}\left(\mathrm{cmol}_{\mathrm{c}} \mathrm{kg}^{-1}\right)$ & 3,7 \\
\hline $\mathrm{Al}^{3+}\left(\mathrm{cmol}_{\mathrm{c}} \mathrm{kg}^{-1}\right)$ & 0,0 \\
\hline $\mathrm{H}+\mathrm{Al}\left(\mathrm{cmol}_{\mathrm{c}} \mathrm{kg}^{-1}\right)$ & 0,05 \\
\hline SB & 14,28 \\
\hline $\mathrm{CTC}_{(\mathrm{pH} 7)}\left(\mathrm{cmol}_{\mathrm{c}} \mathrm{kg}^{-1}\right)$ & 14,33 \\
\hline CEes a $25^{\circ} \mathrm{C}\left(\mathrm{dS} \mathrm{m}^{-1}\right)$ & 9,2 \\
\hline
\end{tabular}

R. Bras. Eng. Agríc. Ambiental, v.10, n.3, p.570-578, 2006. 
partículas, capacidade de campo e ponto de murcha permanente, equivalente de umidade a -10; -100; -300 e -1000 kPa, porosidade total, macroporosidade e microporosidade. As análises químicas incluíram as determinações de: $\mathrm{pH}$ em água; $\mathrm{Ca}^{2+}$ e $\mathrm{Mg}^{2+}$ (extraídos com KCl 1 mol L-1 e determinados por espectrofotometria de absorção atômica), $\mathrm{Na}^{+}$e $\mathrm{K}^{+}$(extraídos com solução de Mehlich-1 e determinados por espectrofotometria de chama); $\mathrm{Al}^{3+}$ (extraído com solução de $\mathrm{KCl} 1 \mathrm{~mol} \mathrm{~L}^{-1}$ e determinado por titulação); $\mathrm{H}^{+}+\mathrm{Al}^{3+}$ (extraídos com solu-

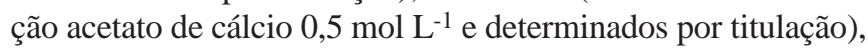
P disponível (extraído com solução de Mehlich-1 e determinado por colorimetria); soma de bases trocáveis (SB), capacidade de troca catiônica a pH 7,0 (CTC). Os resultados das características químicas do extrato de saturação do solo encontram-se na Tabela 2.

Tabela 2. Características químicas do extrato de saturação do material de solo Aluvial eutrófico, do perímetro irrigado de Gorotuba, MG

\begin{tabular}{lc}
\hline Característica & Resultados \\
$\mathrm{pH}$ em água $(1: 2,5)$ & 7,3 \\
$\mathrm{P}\left(\mathrm{mg} \mathrm{kg}^{-1}\right)$ & 27,2 \\
$\mathrm{Na}^{+}\left(\mathrm{cmol}_{\mathrm{c}} \mathrm{kg}^{-1}\right)$ & 73,2 \\
$\mathrm{~K}^{+}\left(\mathrm{cmol}_{\mathrm{c}} \mathrm{kg}^{-1}\right)$ & 0,7 \\
$\mathrm{Ca}^{2+}\left(\mathrm{cmol}_{\mathrm{c}} \mathrm{kg}^{-1}\right)$ & 16,9 \\
$\mathrm{Mg}^{2+}\left(\mathrm{cmol}_{\mathrm{c}} \mathrm{kg}^{-1}\right)$ & 23,6 \\
$\mathrm{Al}^{3+}\left(\mathrm{cmol}_{\mathrm{c}} \mathrm{kg}^{-1}\right)$ & 0,0 \\
$\mathrm{H}+\mathrm{Al}\left(\mathrm{cmol}_{\mathrm{c}} \mathrm{kg}^{-1}\right)$ & 0,05 \\
$\mathrm{CEes} \mathrm{a} 25^{\circ} \mathrm{C}\left(\mathrm{dS} \mathrm{m}^{-1}\right)$ & 9,2 \\
RAS $\left(\mathrm{cmol}_{\mathrm{c}} \mathrm{kg}^{-1}\right)$ & 16,3 \\
\hline
\end{tabular}

A água de irrigação foi analisada para os teores de $\mathrm{Ca}^{2+}, \mathrm{Mg}^{2+}, \mathrm{Na}^{+}, \mathrm{K}^{+}, \mathrm{SO}_{4}{ }^{2-}, \mathrm{Cl}^{-}, \mathrm{CO}_{3}{ }^{2-}$ e $\mathrm{HCO}_{3}{ }^{-}$, além do $\mathrm{pH}$, condutividade elétrica e relação de adsorção de sódio simples e ajustada (Tabela 3).

Tabela 3. Análise química da água natural usada na irrigação

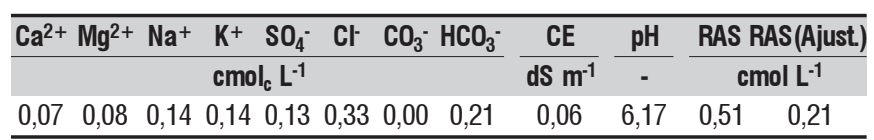

\section{Saturação do solo nos lisímetros e lixiviação}

Realizou-se a saturação do solo utilizando-se uma solução eletrolítica de $\mathrm{CaCl}_{2}$ de $0,5 \mathrm{mM}$, em fluxo ascendente, objetivando-se expulsar os gases e obter um perfil de salinidade semelhante ao observado em condições de campo, cuja maior concentração de sais ao longo do perfil do solo se encontra na superfície, quando se realiza a primeira irrigação.

Na lixiviação de sais estabeleceram-se cinco lâminas de lixiviação, constituídas da solução eletrolítica de cloreto de cálcio, iguais a 0,25, 0,5, 0,75, 1,0 e 1,25 do volume de poros do solo, ou sejam, lâminas de 53, 106, 159, 206 e 248 mm respectivamente.

A aplicação das lâminas de lixiviação foi iniciada no dia 29 de maio de 1999, com solo saturado, aplicando-se $45 \mathrm{~L}$ da solução, em cada lisímetro; em seguida, coletou-se o material lixiviado, de forma fracionada, em volumes de $5 \mathrm{~L}$; após a infiltração dos primeiros $45 \mathrm{~L}$ foram aplicados mais 45 L da solução, sendo o lixiviado coletado da mesma forma anterior completando-se, assim, a aplicação da lâmina de lixiviação $\mathrm{L}_{1}$.

Procedimento semelhante foi usado para os demais tratamentos, até completar o tratamento $\mathrm{L}_{5}$, que recebeu 1,25 do volume de poros, correspondente a dez aplicações intermitentes. Em todas as amostras das frações lixiviadas de $5 \mathrm{~L}$, determinou-se a condutividade elétrica.

\section{Tratamentos e análise estatística}

Estudaram-se dois fatores dispostos em arranjo fatorial, no delineamento inteiramente casualizado, com quatro repetições. O primeiro fator foi a qualidade de água de irrigação (A), obtida da água natural com a adição de sais, de modo a se obter águas, com quatro níveis de concentração, $A_{1}, A_{2}$, $\mathrm{A}_{3}$ e $\mathrm{A}_{4}$, correspondentes às condutividades elétricas de 1,0 , 2,0, 3,0 e 4,0 dS m${ }^{-1}$, a $25^{\circ} \mathrm{C}$, respectivamente. Os sais utilizados foram o bicarbonato de sódio $\left(\mathrm{NaHCO}_{3}\right)$, o cloreto de cálcio hidratado $\left(\mathrm{CaCl}_{2} 2 \mathrm{H}_{2} \mathrm{O}\right)$ e o sulfato de magnésio hidratado $\left(\mathrm{MgSO}_{4} 7 \mathrm{H}_{2} \mathrm{O}\right)$, nas relações, em peso, 11,01 , 17,18 , e $71,81 \%$, respectivamente. Na escolha dos elementos químicos para formar as águas de irrigação, procurou-se usar os sais comumente encontrados nos açudes da região semi-árida do Nordeste brasileiro, segundo Laraque (1989), citado por Molle \& Cadier (1992); o segundo fator refere-se às lâminas de lixiviação (L), em cinco frações, denominadas $\mathrm{L}_{1}, \mathrm{~L}_{2}, \mathrm{~L}_{3}, \mathrm{~L}_{4}$ e $\mathrm{L}_{5}$, correspondentes, também, a 0,25 a 1,25 do volume de poros do material de solo em cada lisímetro, conforme acima mencionado,no delineamento inteiramente casualizado, com quatro repetições.

Utilizou-se a cultura da beterraba (Beta vulgaris L.), cultivar Early Wonder 2000. A semeadura foi realizada no dia 12 de junho de 1999, e o transplantio manual das mudas foi realizado 17 dias após o plantio. Cada lisímetro possuía seis linhas, com 60 mudas, o equivalente a 353.857 plantas ha-1.

Até 25 dias após o transplantio os lisímetros foram irrigados diariamente, com água sem adição de sais, até o estabelecimento das plantas. As irrigações com águas salinas se iniciaram 28 dias após o transplantio; foram realizadas manualmente, empregando-se uma lâmina 100\% da evaporação no tanque classes $\mathrm{A}$, com freqüência de, no máximo, dois dias.

Para retiradas das amostras de solo dos lisímetros confeccionou-se um amostrador, de cobre, com 22 mm de diâmetro e comprimento de $0,8 \mathrm{~m}$. As medidas da salinidade foram realizadas de acordo com Richards (1954), sendo a salinidade expressa em termos da condutividade elétrica do extrato de saturação do solo, em dS m ${ }^{-1}$ a $25{ }^{\circ} \mathrm{C}$.

A condutividade elétrica 1:5 foi determinada segundo o procedimento descrito por Loveday (1974), apud Slavich \& Peterson (1993). A solução foi deixada em repouso durante 24 h, para decantação das partículas do solo, tendo a leitura da condutividade elétrica e da temperatura sido feita, em seguida, com a célula do condutivímetro colocada na solução sobrenadante.

Os valores de condutividade elétrica do extrato de saturação do solo foram correlacionados com a condutividade 
elétrica do extrato sobrenadante 1:5. A calibração foi realizada usando-se 64 amostras de solo, de diferentes níveis de salinidade, empregando-se o modelo linear:

$$
\begin{gathered}
y=5,5786 x \\
R^{2}=0,960
\end{gathered}
$$

em que:

$$
\begin{aligned}
& \text { y - condutividade elétrica do extrato de saturação } \\
& \text { do solo, dS m}{ }^{-1} \text {; e } \\
& \text { x - condutividade elétrica do extrato } 1: 5 \text {, }
\end{aligned}
$$
$(0,2 \leq \mathrm{x} \leq 8,2), \mathrm{dS} \mathrm{m}^{-1}$.

Obteve-se a salinidade média do solo nos lisímetros das amostras retiradas nas profundidades de 20, 25 e $30 \mathrm{~cm}$.

\section{Características da produtividade}

Por unidade experimental, as produtividades total e comercial foram obtidas do valor médio de produtividade das quatro linhas da cultura por lisímetro. As características da produção foram representadas pela produtividade total da cultura (PT) (t ha ${ }^{-1}$ ) e pela produtividade comercial ( $\left.\mathrm{t} \mathrm{ha}^{-1}\right)$, quando se levou em conta a seleção da beterraba nos diâmetros seguintes: diâmetro maior que $3 \mathrm{~cm}$ (DM3), diâmetro maior que 4 cm (DM4), diâmetro maior que 5 cm (DM5), diâmetro maior que $6 \mathrm{~cm}$ (DM6) e diâmetro maior que 7 cm (DM7).

\section{RESULTADOS E DISCUSSÃO}

\section{Eficiência da lixiviação}

A Figura 1 mostra a variação da condutividade elétrica do lixiviado, após a aplicação das lâminas de lixiviação, com uso de uma solução eletrolítica de cloreto de cálcio 0,5 mM. Observa-se que o valor da condutividade elétrica do efluente aumentou com a lâmina de lixiviação até a lâmina equivalente a um volume de poros. Nesse ponto, a condutividade elétrica máxima do efluente atingiu 13,2 dS m-1 e a partir daí começou a decrescer. Tal fato aconteceu porque houve deslocamento dos sais que, inicialmente, estavam concentrados na superfície do solo. Com a aplicação da lâmina de li-

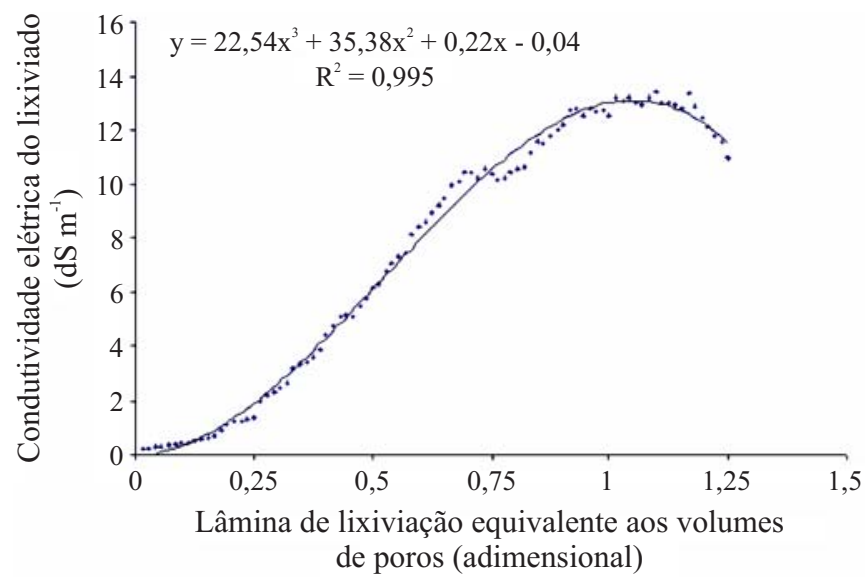

Figura 1. Estimativa da condutividade elétrica do material lixiviado dos lisímetros, em função das lâminas de lixiviação xiviação equivalente a 1,25 do volume de poros, houve decréscimo na CE do efluente, ou seja, 10,95 dS m-1, relativamente ao valor máximo de 13,2 dS m- Richards (1954), Daker (1984), Pizarro (1985) e Ferreira (2002), afirmam que a diminuição da quantidade de sais solúveis envolve o simples processo de solubilização e a conseqüente remoção pela água de percolação.

A Figura 2 apresenta a distribuição da salinidade média no perfil do solo nos lisímetros. Nos lisímetros que receberam a lâmina de lixiviação equivalente a 0,25 do volume de poros, a concentração dos sais foi maior na camada 0 a $15 \mathrm{~cm}$ (18,0 dS m-1) enquanto nas lâminas maiores a maior concentração dos sais foi observada na camada 15 a $30 \mathrm{~cm}$. Verifica-se, ainda, que houve redução gradativa da concentração de sais à medida que as lâminas de lixiviação foram aumentadas e que, a partir da lâmina equivalente a 1,0 volume de poros, a diferença de concentração salina entre as camadas foi praticamente nula.

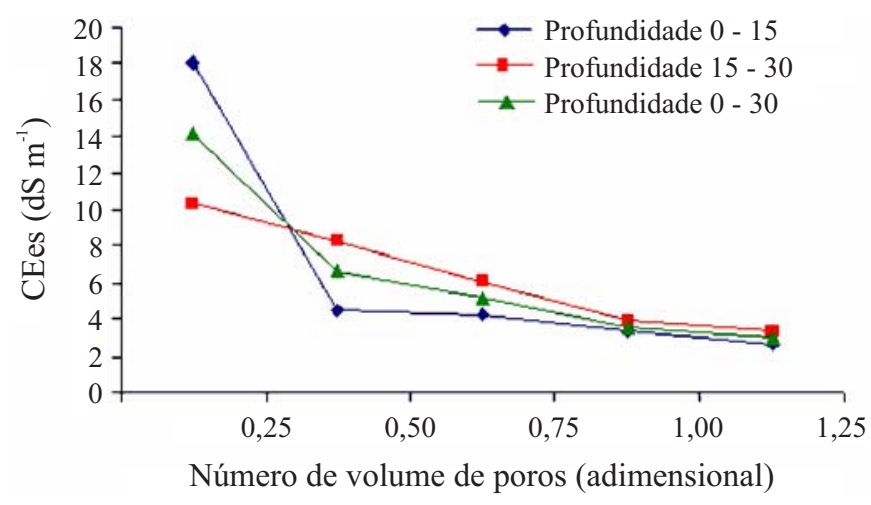

Figura 2. Condutividade elétrica do extrato de saturação do solo dos lisímetros em função do número de volume de poros nas faixas de profundidades de 0 a 15, de 15 a 30 e de 0 a $30 \mathrm{~cm}$, ao final do experimento

A medida em que a lâmina de lixiviação aumentou (Figuras 1 e 2) o incremento na concentração salina do efluente, foi notório, indicando a ocorrência de perda de sais do perfil do solo, confirmadas pela diminuição da concentração salina no perfil do solo para as profundidades de 0 a 15 e de 15 a $30 \mathrm{~cm}$. A maior concentração dos sais encontrava-se na superfície do solo e diminuía com a profundidade. Essa distribuição foi obtida em função do umedecimento do solo nos lisímetros ter sido feito de baixo para cima. Segundo Daker (1984) referida distribuição é típica de solos salinizados por movimento de água ascendente do lençol freático, seguido da evapotranspiração na sua superfície.

De modo geral, na camada de 0 a $15 \mathrm{~cm}$, possivelmente em razão da evaporação superficial e da absorção pelo sistema radicular, ocorreu acréscimo da concentração salina durante o experimento, sendo este mais evidente para as águas de irrigação com maiores concentrações salinas.

Na Figura 3 podem ser observados os efeitos das lâminas de lixiviação na salinidade do solo, quando a salinidade da água de irrigação foi mantida constante. Vê-se que, para as lâminas de lixiviação L1 e L2, o solo apresentou valores de salinidade maiores e mais instáveis, enquanto para as lâminas 

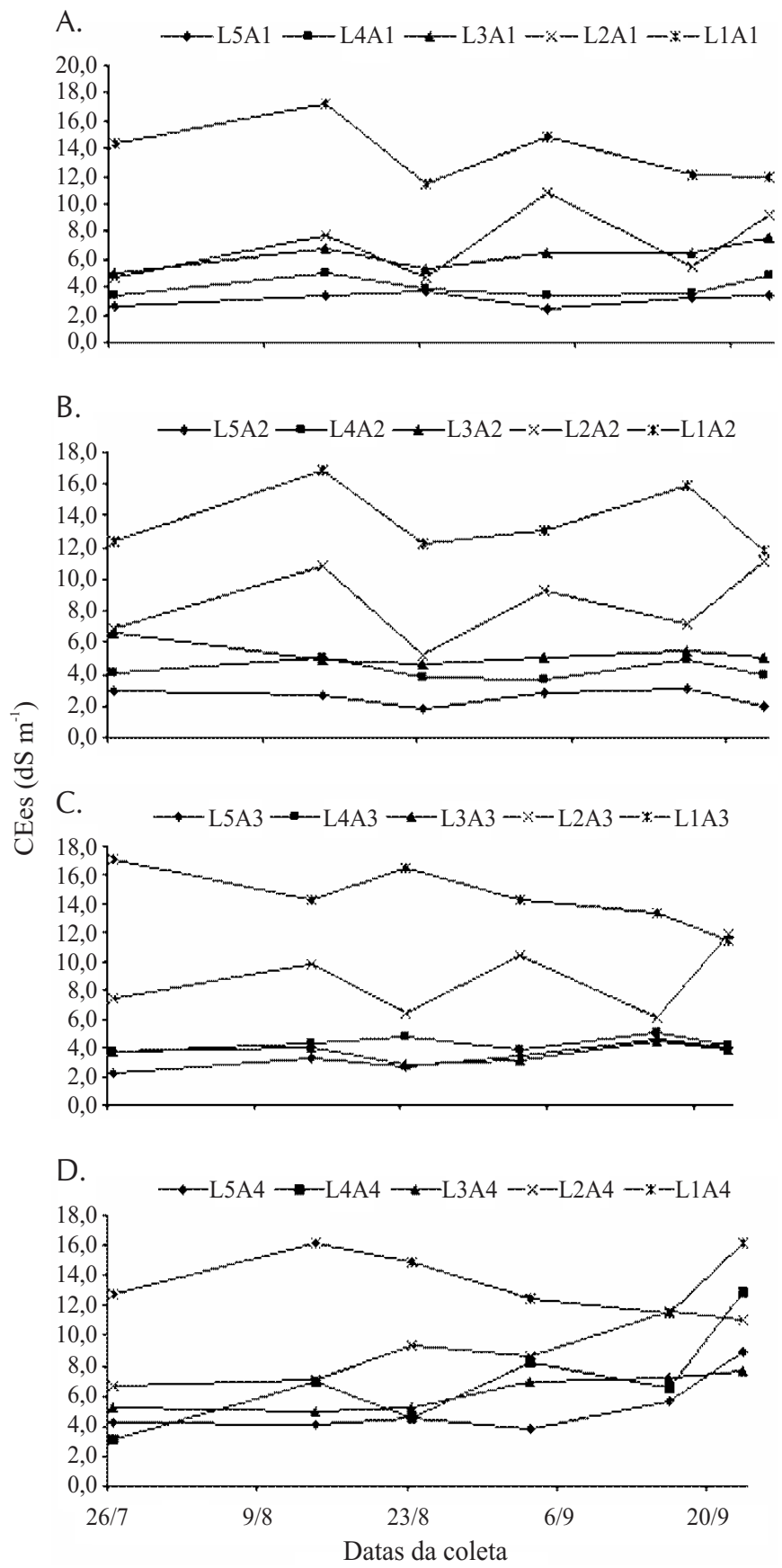

Figura 3. Condutividade elétrica do extrato de saturação do solo $(0-30 \mathrm{~cm})$ fixando a qualidade da água $(A=A 1 ; B=A 2 ; C=A 3$ e $D=A 4)$ e variando as lâminas de lixiviação, ao longo dos respectivos dias de coleta

de lixiviação L3, L4 e L5 os valores foram menores e mais estáveis (Figura 3A, 3B, 3C e 3D). Os tratamentos com a água de irrigação A4 apresentaram incremento na salinidade do solo, para as lâminas de lixiviação L2, L3, L4 e L5. Todavia, para a lâmina de lixiviação L1 ocorreu decréscimo na salinidade do solo a partir da segunda coleta de solo devido, provavelmente, ao fato do solo se encontrar com a salinidade mais elevada e a água de irrigação A4 ter provocado sua lixiviação para a profundidade abaixo de $30 \mathrm{~cm}$.

Na Figura 4 observa-se o efeito da qualidade da água de irrigação na salinidade do lixiviado $\left(\mathrm{CE}_{\mathrm{LX}}\right)$ para as lâminas de lixiviação constantes.

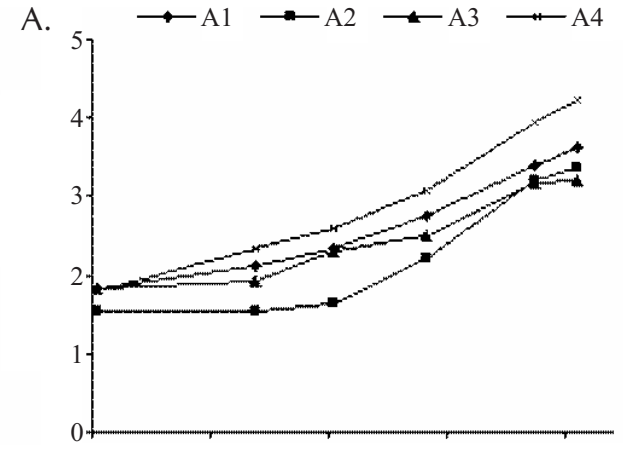

B.
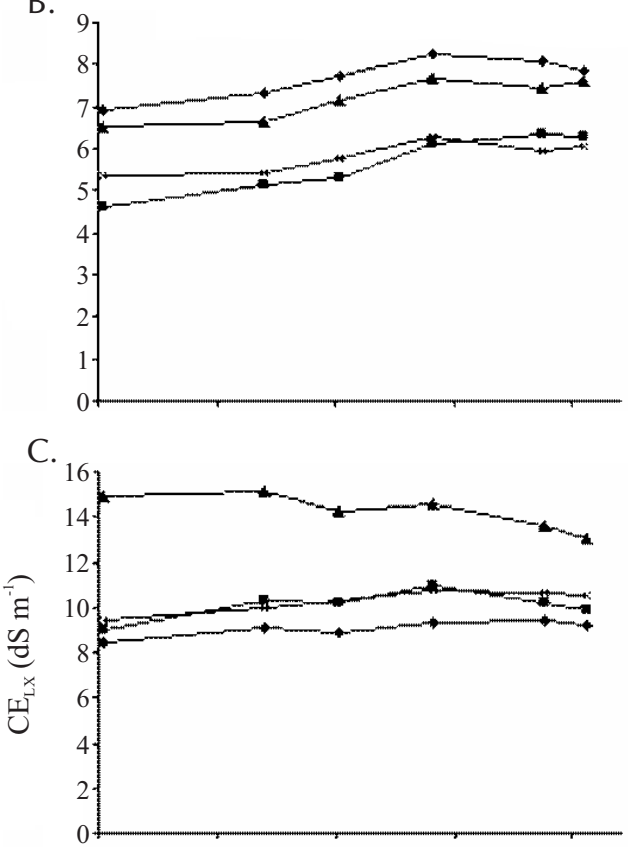

D.

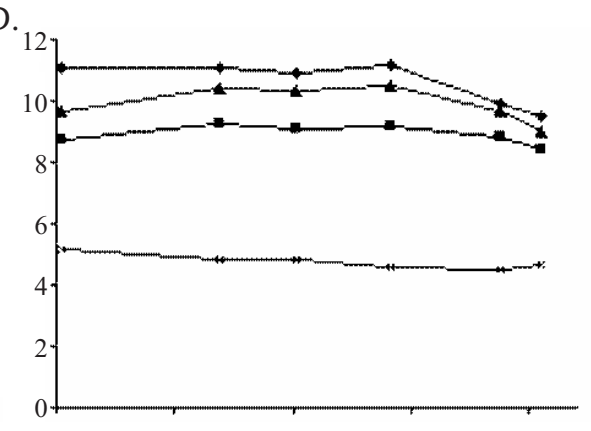

E.

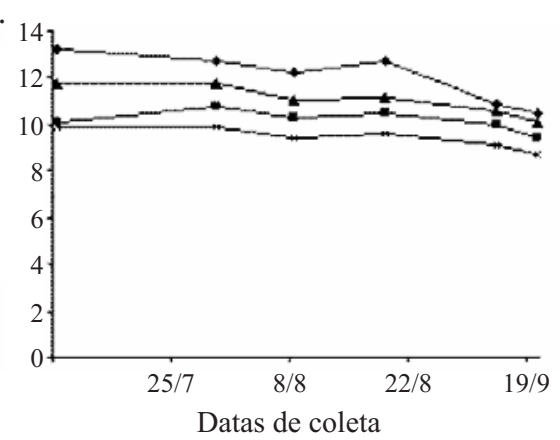

Figura 4. Condutividade elétrica do lixiviado nos respectivos períodos de coleta no decorrer do experimento, considerando-se os efeitos de salinidade da água de irrigação $\left(A_{1}=1,0, A_{2}=2,0, A_{3}=3,0, A_{4}=4,0 \mathrm{dS} \mathrm{m}^{-1}\right)$ e se fixando as lâminas de lixiviação equivalente a 0,25 (A), 0,50 (B), 0,75 (C), 1,00 (D) e 1,25 (E) do volume do poros do solo 
De maneira geral, a concentração salina do lixiviado tendeu a aumentar com o decorrer do tempo, para as lâminas de lixiviação L1 e L2 (Figura 4A e 4B); tal comportamento é semelhante ao que ocorre em áreas irrigadas onde são usadas baixas frações de lixiviação, ou seja, a salinidade aumenta com a profundidade da zona radicular, com o decorrer do tempo de irrigação (Ayers \& Westcot, 1991). Para a lâmina L3, Figura 4 (C), a salinidade do lixiviado permaneceu praticamente inalterada, mostrando que houve compensação entre sais lixiviados e adicionados ao solo pela água de irrigação, mas a combinação L3A3, que divergiu dos demais tratamentos, apresentando salinidade bem mais elevada no início, declinando no final. Para as lâminas L4 e L5 (Figuras $4 \mathrm{D}$ e $4 \mathrm{E}$ ), notou-se tendência de queda da salinidade a partir da quarta amostragem, em razão da intensa lixiviação promovida pelas lâminas L4 e L5, em contraposição a um pequeno aporte de sais via água de irrigação. Inexplicavelmente, a combinação L4A4, Figura 4 (D), divergiu dos demais tratamentos.

Os efeitos das lâminas de lixiviação sobre a salinidade do lixiviado podem ser observados na Figura 5, quando a salinidade da água de irrigação foi mantida constante. Na figura anterior verifica-se que os tratamentos que receberam as lâminas de lixiviação L1 e L2 apresentaram os menores valores de salinidade no lixiviado.

Os tratamentos que receberam a lâmina de lixiviação L3 (Figura 5B, 5C, e 5D) apresentaram os maiores valores de salinidade, com exceção dos tratamentos que receberam a água de irrigação A1, Figura 5 (A). Os tratamentos que receberam a lâmina de lixiviação L5, superaram os valores dos tratamentos com a lâmina L4 mas, de modo geral, esses valores foram bem próximos, exceto para os tratamentos que

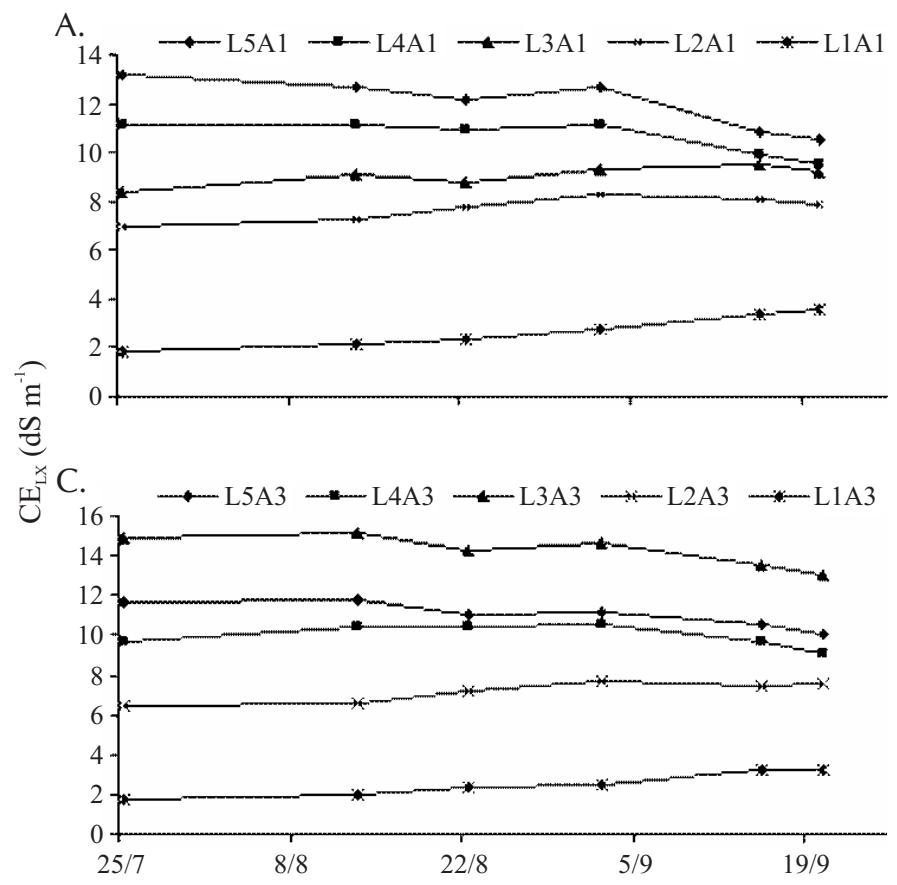

receberam a água de irrigação A4, Figura 5 (D), em que a combinação L4A4 apresentou valores bem inferiores.

A Figura 5 (D) mostra uma salinidade quase estável no decorrer do experimento, para as combinações L5A4, L4A4 e L2A4, enquanto a combinação L1A4 mostra, desde o início da coleta de dados, salinidade crescente no lixiviado.

Avaliação do perfil de salinidade final do solo dos lisímetros

Fixando-se as lâminas de lixiviação e variando os níveis de salinidade da água de irrigação (Figura 6A) na lâmina de lixiviação L5, a salinidade final do solo para a profundidade de 0 a $10 \mathrm{~cm}$ oscilou de 4,8 a 6,6 dS m $\mathrm{m}^{-1}$ e decresceu gradativamente nas faixas de maiores profundidades, oscilando de 2,0 a 3,1 dS m-1, na faixa de 20 a $30 \mathrm{~cm}$.

Para a lâmina de lixiviação L1 (Figura 6E), constata-se que a salinidade oscilou de 18 a $23 \mathrm{dS} \mathrm{m}^{-1}$ na faixa de 0 a $10 \mathrm{~cm}$, decrescendo para as faixas de maiores profundidades, tendo variado de 8,0 a $10,0 \mathrm{dS} \mathrm{m}^{-1}$ na faixa de 20 a $30 \mathrm{~cm}$. Para as lâminas de lixiviação L2, L3 e L4, Figura 6 (B, C e D), foi maior a oscilação para os valores da condutividade elétrica do solo para os diversos níveis de salinidade da água de irrigação e a salinidade do extrato de saturação do solo foi mais elevada em praticamente todas as faixas de profundidade, para a água de irrigação A4, o que demonstra que a salinidade final do solo foi influenciada pelo maior nível de salinidade da água de irrigação.

Fixando-se os níveis de salinidade da água de irrigação e variando os níveis das lâminas de lixiviação do solo observa-se (Figura 7C e 7D) que para os diversos níveis de qualidade da água de irrigação a salinidade final do solo foi maior para as lâminas de lixiviação L1 e L2 e menor para L5 e L3, nas diversas faixas de profundidade.

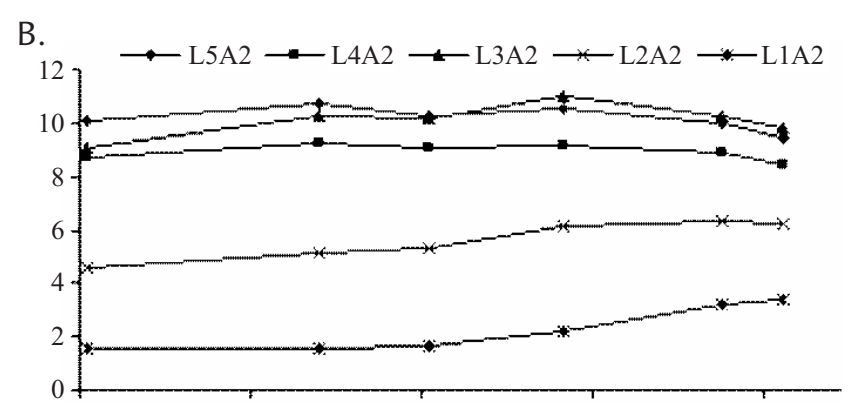

D.

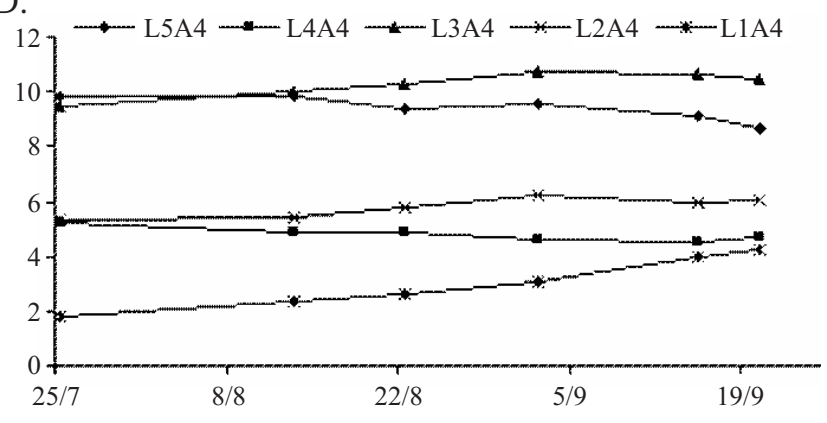

Figura 5. Condutividade elétrica do lixiviado nos períodos de coleta de fechamento dos balanços hídricos, ao longo do experimento, para diferentes combinações de lâminas de lixiviação $L_{1}=0,25, L_{2}=0,50, L_{3}=0,75, L_{4}=1,00$ e $L_{5}=1,25$ volume do poros do solo e qualidades da água de irrigação $\left(A_{1}=1,0, A_{2}=2,0, A_{3}=3,0, A_{4}=4,0 \mathrm{~d} S \mathrm{~m}^{-1}\right)$ 
A. $\longrightarrow \mathrm{L} 5 \mathrm{~A} 1 \rightarrow \mathrm{L} 5 \mathrm{~A} 2 \rightarrow \mathrm{L} 5 \mathrm{~A} 3 \longrightarrow \mathrm{L} 5 \mathrm{~A} 4$

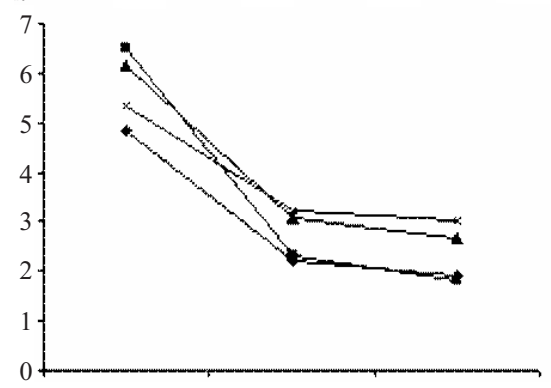

B. $\rightarrow-\mathrm{L} 4 \mathrm{~A} 1 \rightarrow-\mathrm{L} 4 \mathrm{~A} 2 \rightarrow-\mathrm{L} 4 \mathrm{~A} 3 \rightarrow-\mathrm{L} 4 \mathrm{~A} 4$

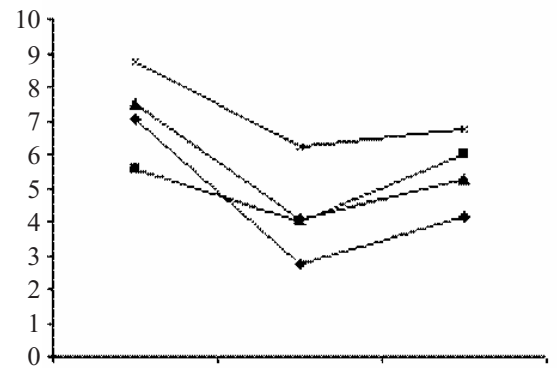

C. $\longrightarrow \mathrm{L} 3 \mathrm{~A} 1 \rightarrow-\mathrm{L} 3 \mathrm{~A} 2-\mathrm{L} 3 \mathrm{~A} 3 \longrightarrow \mathrm{L} 3 \mathrm{~A} 4$

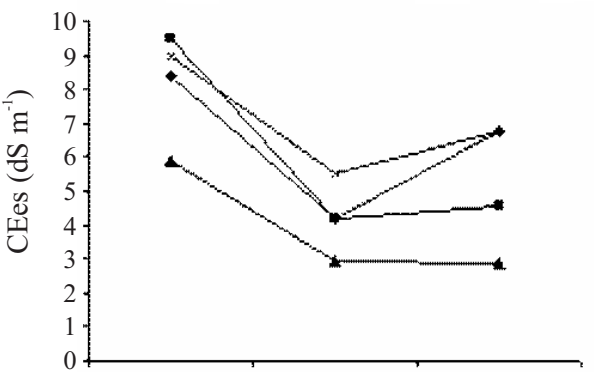

D. $\longrightarrow \mathrm{L} 2 \mathrm{~A} 1 \rightarrow \mathrm{L} 2 \mathrm{~A} 2 \longrightarrow \mathrm{L} 2 \mathrm{~A} 3 \longrightarrow \mathrm{L} 2 \mathrm{~A} 4$

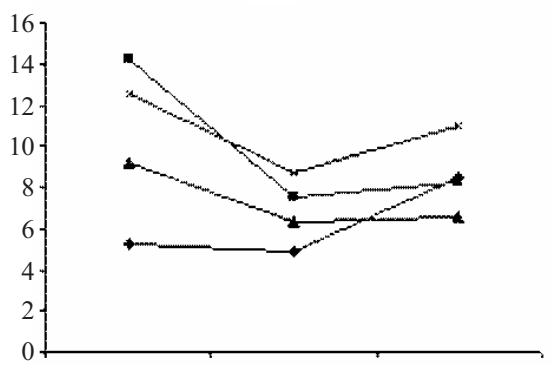

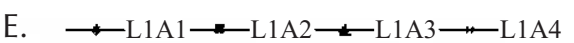

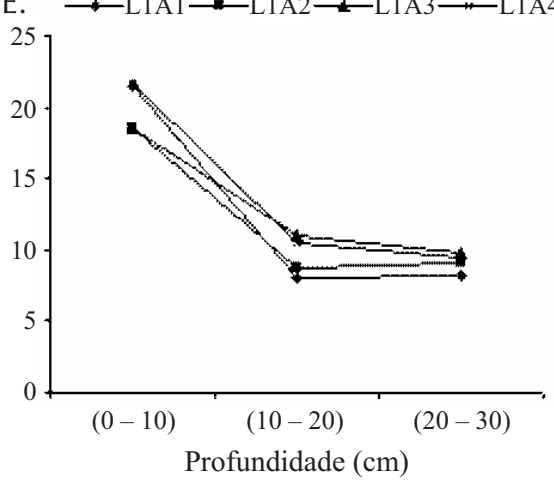

Figura 6. Valores da condutividade elétrica do extrato de saturação do solo para o perfil de salinidade final do solo, nas profundidades de 0 a 10 , de 10 a 20 e de 20 a $30 \mathrm{~cm}$, dos diferentes lâminas de lixiviação $L_{1}=0,25$, $\mathrm{L}_{2}=0,50, \mathrm{~L}_{3}=0,75, \mathrm{~L}_{4}=1,00$ e $\mathrm{L}_{5}=1,25$ volume do poros do solo) $\mathrm{e}$ salinidade de água $\left(A_{1}=1,0, A_{2}=2,0, A_{3}=3,0, A_{4}=4,0 \mathrm{dS} \mathrm{m} \mathrm{m}^{-1}\right)$
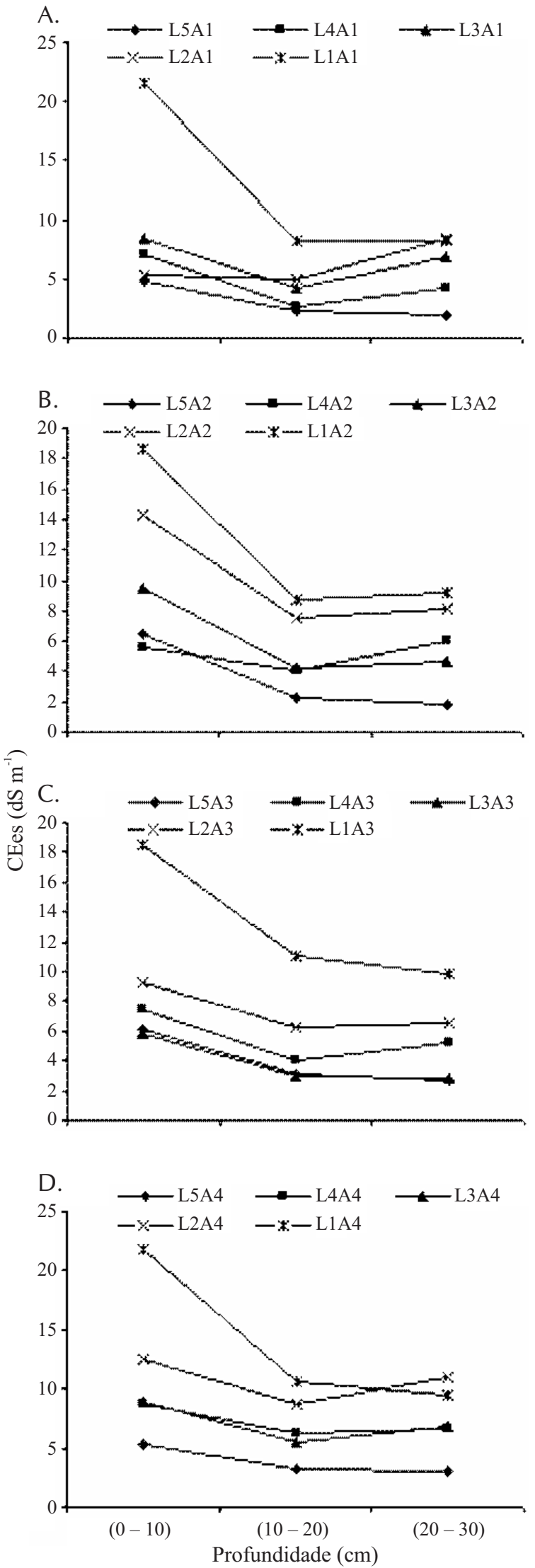

Figura 7. Valores da condutividade elétrica do extrato de saturação do solo para o perfil de salinidade final do solo, nas profundidades de 0 a 10 , de 10 a 20 e de 20 a $30 \mathrm{~cm}$, dos diferentes lâminas de lixiviação $L_{1}=0,25$, $\mathrm{L}_{2}=0,50, \mathrm{~L}_{3}=0,75, \mathrm{~L}_{4}=1,00$ e $\mathrm{L}_{5}=1,25$ volume do poros do solo) $\mathrm{e}$ salinidade de água $\left(A_{1}=1,0, A_{2}=2,0, A_{3}=3,0, A_{4}=4,0 \mathrm{dS} \mathrm{m} ~ m^{-1}\right)$ 
Os resultados indicam que os valores das lâminas de lixiviação foram decisivos na eliminação dos sais no perfil do solo, para os diversos níveis da salinidade da água de irrigação.

Comportamentos adversos foram observados para os tratamentos L2A1 (Figura 7A), e L4A2 (Figura 7B), na camada 0 a $10 \mathrm{~cm}$, quando em ambos os valores da condutividade elétrica do extrato de saturação do solo foram inferiores aos demais observados para as respectivas lâminas de lixiviação, fato que pode ter ocorrido devido às falhas nos pontos de amostragem, na coleta do solo.

\section{Características da produtividade}

O resumo das análises de variância encontra-se na Tabela 4. A produtividade total e das raízes com diâmetros mai- ores que 3, 4, 5, 6 e 7 cm, não foi influenciada pelos níveis da salinidade da água de irrigação e lâminas de lixiviação, possivelmente por se tratar de uma cultura moderadamente tolerante à salinidade, indicando que a beterraba pode ser cultivada nessas condições experimentais.

A produtividade de raízes de beterraba irrigada com águas salinas, sob diferentes lâminas de lixiviação, resultou num rendimento médio de $37,5 \mathrm{t} \mathrm{ha}^{-1}$, mostrando a possibilidade do uso de água salina na irrigação da cultura tendo em vista que Ricci et al. (2000), trabalhando com a mesma cultivar, no Estado de Rio de Janeiro, obteve produtividade de 30,6 t ha-1. Deve-se ressaltar que, de acordo com o IEA/CATI (2001), apud Fonseca (2001), a média da produtividade obtida no experimento (37,5 $\left.\mathrm{tha}^{-1}\right)$ está acima da produtividade média do Estado de São Paulo $\left(21,4 \mathrm{t} \mathrm{ha}^{-1}\right)$.

Tabela 4. Análise de variância e coeficiente de variação (CV) das variáveis produtividades total (PT) e produtividades com diâmetro maior que 3 (DM3), 4 (DM4), 5 (DM5), 6 (DM6) e 7 cm (DM7), em t ha-1 , em função das lâminas de lixiviação (L) e da condutividade elétrica da água de irrigação (A)

\begin{tabular}{|c|c|c|c|c|c|c|c|}
\hline \multirow{2}{*}{ Fonte de Variação } & \multirow{2}{*}{ GL } & \multicolumn{6}{|c|}{ Quadrados Médios } \\
\hline & & PT & DM3 & DM4 & DM5 & DM6 & DM7 \\
\hline $\mathrm{L}(\% \mathrm{VP})$ & 4 & $51,842^{\mathrm{ns}}$ & $49,468^{n s}$ & $50,180^{\text {ns }}$ & $61,325^{\mathrm{ns}}$ & $164,02^{\mathrm{ns}}$ & $82,008^{\text {ns }}$ \\
\hline$A\left(d S m^{-1}\right)$ & 3 & $45,207^{\mathrm{ns}}$ & $43,388^{\text {ns }}$ & $50,242^{\mathrm{ns}}$ & $100,64^{\mathrm{ns}}$ & $218,86^{\mathrm{ns}}$ & $165,92^{\text {ns }}$ \\
\hline $\mathrm{L} \times \mathrm{A}$ & 12 & $37,473^{\text {ns }}$ & $34,650^{\text {ns }}$ & $43,826^{\mathrm{ns}}$ & $60,595^{\mathrm{ns}}$ & $74,014^{\mathrm{ns}}$ & $103,83^{\text {ns }}$ \\
\hline Resíduo & 60 & 59,065 & 57,682 & 62,009 & 79,531 & 131,104 & 80,430 \\
\hline CV \% & & 16,42 & 16,29 & 17,15 & 20,83 & 33,35 & 52,66 \\
\hline
\end{tabular}

ns Não-significativo (10\% probabilidade pelo teste $\mathrm{F})$.

\section{CONCLUSÕES}

1. As menores lâminas de lixiviação proporcionaram os maiores incrementos de salinidade no lixiviado do solo.

2. A salinidade no perfil do solo aumentou com a salinidade da água e com a redução da fração de lixiviação.

3. A beterraba tolerou a elevação de sais no ambiente, não tendo sua produção afetada pela salinidade e manejo da água.

\section{LITERATURA CITADA}

Ayers, R. S.; Westcot, D. W. A qualidade da água na agricultura. Campina Grande: UFPB, 1991. 218p.

Bernardo, S. Manual de Irrigação. 6.ed. Viçosa: UFV, 1995. 657p.

Cordeiro, G. Salinidade em áreas irrigadas. Petrolina, PE. Embrapa Semi-Árido, 2001. http://www.cpatsa.embrapa.br/artigos/ salinidade.html. 18 Mai. 2003.

Cordeiro, G. G.; Barreto, A. N.; Carvajal, A. C. N. Levantamento das condições de salinidade e sodicidade do Projeto de Irrigação de São Gonçalo ( $2^{\text {a }}$ parte). Petrolina: Embrapa-CPATSA, 1988. 57p. Documentos, 54

Daker, A. A Água na Agricultura: Irrigação e Drenagem. 6.ed. v.3. Rio de Janeiro: Freitas Basto, 1984. 543p.

EMBRAPA - Empresa Brasileira de Pesquisa Agropecuária. Serviço nacional de Levantamento e Conservação de Soos. Manual de métodos de análises do solo. Rio de Janeiro: EMBRAPA, 1997. 60p.
Fageria, N. K.; Gheyi, H. R. Melhoramento genético das culturas e seleção de cultivares. In: Gheyi, H. R.; Queiroz, J. E.; Medeiros, J. M. (ed.). Manejo e controle da salinidade na agricultura. Campina Grande: UFPB-SBEA, 1997. p.363-383.

Ferreira, P. A. Qualidade de água e manejo água-planta em solos salinos. Brasília: ABEAS, Viçosa: UFV, 2002. 141p. Curso de Engenharia e Manejo de Irrigação. Módulo, 10

Fonseca, T. G. Produção de mudas de hortaliças em substratos de diferentes composições com adição de $\mathrm{CO}_{2}$ na água de irrigação. Piracicaba: ESALQ/USP, 2001. 72p. Dissertação Mestrado

Ghassemi, F.; Jakeman, A. J.; Nix, H. A. Salinization of land and water resources: Human causes, extent, management and case studies, Wallingford: CAB International, 1995. 526 p.

Khan, M. A.; Abdullah, Z. Salinity - sodicity induced changes in reproductive physiology of rice (Oryza sativa L.) under dense soil conditions. Environmental and Experimental Botany, Paris, v.49, n.2, p.145-157, 2003.

Laraque, A. Estudo e previsão da qualidade química da água dos açudes do Nordeste Semi-árido Brasileiro. Recife: SUDENE/ DPG/PRN, 1989. 95p.

Molle, F.; Cadier, E. Manual do pequeno açude. Recife: SUDENE-DPG-PRN-DPP- APR, 1992. 521p.

Pizarro, F. Drenaje agricola y recuperacion de suelos salinos. 2.ed. Madrid: Agricola Espanola, 1985. 521p.

Rhoades, J. D.; Chanduvi, F.; Lesch, S. Soil Salinity Assessment: Methods and interpretation of electrical conductivity measurements. Rome: FAO, 1999. 150p. (Irrigation and drainage) Paper n.57.

R. Bras. Eng. Agríc. Ambiental, v.10, n.3, p.570-578, 2006. 
Ricci, M. dos S. F.; Almeida, D. L. de; Fernandes, M. do C. A.; Ribeiro, R. de L. D.; Cantanheide, M. C. dos S. Efeitos da solarização do solo na densidade populacional da tiririca e na produtividade de hortaliças sob manejo orgânico. Pesquisa Agropecuária Brasileira, Brasília, v.35, n.11, p.2175-2179, 2000.

Richards, L. A. Diagnosis and improvement of saline and alkali soils. Washington D.C.: US Department of Agriculture, 1954. 160p.
Slavich, P. G.; Peterson, G. H. Estimating a electrical conductivity of saturated paste extracts from 1:5 soil: water suspensions and texture. Australian Journal of Soil Research, Collingwood, v.31, n.1, p.73-81, 1993.

UFV - Universidade Federal de Viçosa. Levantamento de reconhecimento dos solos da bacia de irrigação do Rio Gorutuba (Projeto Bico-da-Pedra). Viçosa: UFV, 1969. 143p. 